\title{
Sample Derived from New Primary
}

National Cancer Institute

\section{Source}

National Cancer Institute. Sample Derived from New Primary. NCI Thesaurus. Code C156441.

A biospecimen derived from a new primary tumor. 